\title{
Engineered Protein Adhesive Gel as an Osteo Conductive Material for Bone Healing
}

\author{
Manikandan A, Thirupathi Kumara Raja S, Thiruselvi T, and Gnanamani A* \\ Microbiology Division, Biological Material Laboratory, India
}

Submission: June 15, 2017; Published: July 13, 2017

*Corresponding author: Gnanamani A, Microbiology Division, Biological Material Laboratory, CSIR-CLRI, Adyar, Chennai 600 020, Tamil Nadu, India, Email: gnanamani3@gmail.com

\begin{abstract}
The present study explores the bone fracture repairing efficacy of an engineered protein in detail. Engineered protein prepared using phenolic acids and gelatin demonstrated adhesive property under in-situ condition while subjected to oxidation. The experimental groups include control and sample treatment and all the experiments were conducted in Albino rats in Tibia. Followed by the fracture, the glue was applied and subjected to casting. Healing or rejoining of bone was assessed using X-ray, SEM and H\&E sectioning of repaired bone tissue at zero and $30^{\text {th }}$ day. Results revealed that engineered protein supports bone fracture repair at faster rate compared to control. Both SEM and H\&E sections also corborates well with the repairing pattern observed. The presence of minerals and the in-situ gelation property of the engineered protein promote the repair as expected.
\end{abstract}

Keywords: Bioadhesive; Hydrogel; Gelatin; Caffeic acid; Fracture bone repair

\section{Introduction}

The current sceanrio in the development of health care materials introduced numerous biological materials [1,2]. Most of the biological materials target skin and wounds and only few materials focused the internal organs [3]. Bone, an important organ and if there is any critical injury or fracture it needs immediate attention. To fix a bone fracture surgeons use metal screws, pins, rods or plates to hold the bones in the place [4]. However, these materials needs to be removed (by another surgery) once the bone got repaired. In recent years, tissue regeneration, an important research area paves a way to have remediation through supporting materials in the form of biomaterials. Since, most of the biomaterials are from synthetic followed by natural, the biocompatibility and immunological issues restrict the benefits [5]. Our recent research on the development of tissue approximation agent for cut wounds demonstrated interested results for both external and internal tissue approximation [6,7]. The tissue approximation agent used in the present study is an engineered protein which under insitu condition acts as a glue and fix the fracture. Since, there is no biological glue is available for fixing the bone fracture, in the present study, an attempt was made to explore the bone fracture repairing efficacy of the engineered protein glue in small animals models.

\section{Experimental Methods}

\section{Preparation of the PAMG and PAMG-gel}

Phenolic acid modified gelatin (PAMG) prepared through EDC/NHS chemistry as per the reported literature [6,7]. To prepare PAMG-gel, in brief, $2 \mathrm{ml}$ of $16 \%(\mathrm{w} / \mathrm{v}$ ) PAMG solution was prepared and treated with $50-100 \mu \mathrm{l}$ of $2 \%(\mathrm{w} / \mathrm{v})$ sodium metaperiodate. The transformation of PAMG solution to the gel state was termed as PAMG-gel.

\section{In-vivo bone healing studies: animal model}

To access the bone fracture repair efficacy, in the present study we used tibia bone fracture model [8]. All the studies were performed upon Institute ethical approval. Six male albino rats (wistar strain) were segregated into two groups: (i) untreated (Control) and (ii) PAMG-gel treated group. The animals were housed in standard animal cages and fed with pelletized feed and surplus water. The house temperature was maintained at $25{ }^{\circ} \mathrm{C}$ with a 12 hour light-dark cycle.

The rat was anesthetized by the intra-peritoneal injection of ketamine: Xylazine $(60: 20 \mathrm{mg} / \mathrm{kg}$ body weight). The left hind tibia was taken for the bone fracture study. The operative site was dehaired and sterilized with provide on iodine solution. The 
bone was fractured using a side cutting diamond disk and high speed micro motor under an abundant irrigation with sterile solution. Experimental animals receiving sample treatment was indented with PAMG-gel on site to fix the fracture and the control animals are left as such by simple fixing. Both the animals groups and the injured skin site was approximated with restorable sutures and provided with orthopaedic casting. All the animals were undisturbed until the end of the experiment. Upon healing, $\mathrm{X}$-ray imaging was performed to analyze the rejoining efficacy. Further, all the animals were sacrificed and the experimental bone was removed for further SEM and H\&E analysis.

\section{Results and Discussion}

In general, bone has an intrinsic healing capacity and it does not require any healing agent to rejoin upon fracture [9]. However, rejoining of bone requires proper guiding and requires additional supporting factors for the faster rejoining and strengthening of the bone. With regard to complex bone fracture repair, conventional screws and plates are not helpful and the patients undergo number of surgery. Rejoining the bone fracture with suitable adhesives of either synthetic or natural origin with high compatibility is always a welcoming idea for the orthopaedic surgeons [10]. However, till now there are no specific adhesives have been designed as per the clinical requirement. Decades before several synthetic adhesive were in the clinical markets and now excluded for its biocompatible and biodegradable properties. Though natural materials like fibrin and gelatin were taken into consideration, the inherent low mechanical property restricts its applications. Our previous report on the mussel mimicking biological adhesives for skin approximation widens the scope, for several other 3 applications $[6,7]$. PAMG-gel is a composition of gelatin conjugated with phenolic acid. Gelatin, the hydrolyzed form of collagen is an integral protein in bone formation. Reported literature suggests that mechanically stable hydrogel act as osteo conductive materials for bone tissue regeneration [11]. The present study exploits bone fracture repairing efficacy of the PAMG-gel as an inherent osteo conductive protein and as a bone adhesive.

Preparation and characterization of the PAMG were discussed in our earlier paper. Further PAMG-gel was prepared by oxidizing the PAMG solution with mild oxidizing agents. The phenolic acids conjugated to the gelatin (From Fish scale collagen) backbone further undergoes Michael's addition reaction to form inter and intra molecular cross linking with the protein and forms a gel like material. This reaction was performed on-site to imitate the approximation the bones and tissues.

In-vivo tibial fracture model was performed to access the bone healing efficacy of the PAMG-gel. During the course of the study all the animals remained healthy and observed for 30 days for the complete joining of the bone. At scheduled time interval, the walking pattern and speed of the rat was analyzed physically. It has been found that from third week onwards the PAMGgel treated group can able to give a normal walking posture, whereas for the untreated wound, the walking pattern were not the same as earlier. On, day $30 \mathrm{X}$-ray imaging was performed for all the rats, from the results (Figure 1) we can able to conclude that the PAMG-gel treated rat shows improved repair pattern on comparing with the untreated group. Though the untreated fractured bone shows the rejoined structure in the X-ray imaging, the morphology of the rejoined bone was different. Further the animals were sacrificed to excise the fractured bone. The ex-vivo images of both the untreated and PAMG-gel treated were shown as a representative image in the Figure 1 . The untreated wound shows calcification in the rejoined bone area whereas the PAMGgel treated wound was very clean and equal to that of that of the normal bone. Further, the SEM images of the ex-vivo bone show a clean repair pattern for the PAMG-gel treated bone, whereas for the untreated bone, due to calcification, the bone appears porous and minor cracks were seen. Similarly, results from the H\&E section of the cross sectioned bone shows high porous structure for the untreated group were as for the PAMG-gel treated group shows dense packed bone structure.

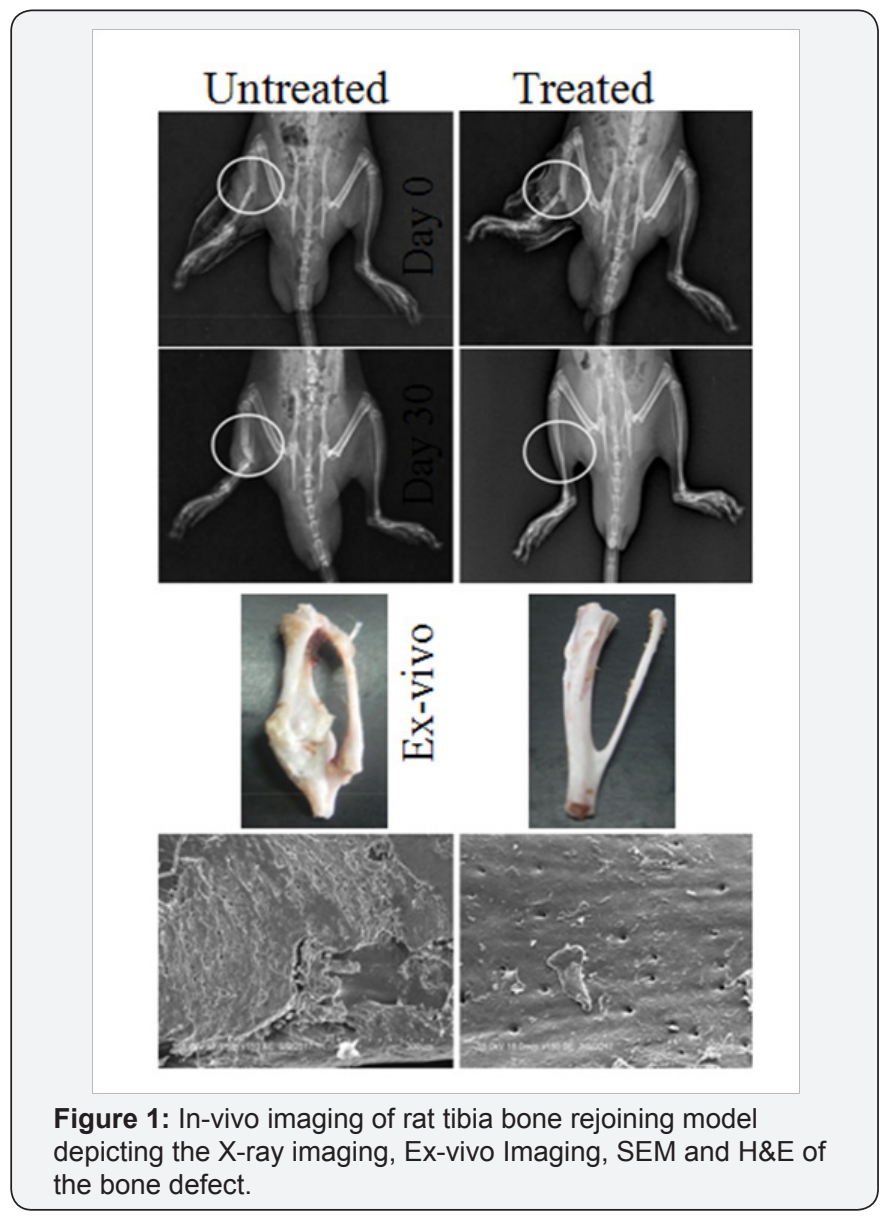

\section{Conclusion}

The present studies evidently proves that in-situ gelation of phenolic acid engineered protein repair bone fracture without any calcification and thus avoid the use of metal screws and plates. 


\section{References}

1. Langer R, Tirrell DA (2004) Designing materials for biology and medicine. Nature 428(6982): 487-492.

2. Williams DF (2009) On the nature of biomaterials. Biomaterials 30(30): 5897-5909.

3. Ozbolat IT, Yu Y (2013) Bioprinting toward organ fabrication: challenges and future trends. IEEE Trans Biomed Eng 60(3): 691-699.

4. Nandi S, Roy S, Mukherjee P, Kundu B, De D, et al. (2010) Orthopaedic applications of bone graft \& graft substitutes: a review. Indian J Med Res 132: 15-30.

5. Remes A, Williams D (1992) Immune response in biocompatibility. Biomaterials 13(11): 731-743.

6. Raja STK, Thiruselvi T, Aravindhan R, Mandal AB, Gnanamani A (2015) In-vitro and in-vivo assessments of a 3-(3, 4-dihydroxyphenyl)-2propenoic acid bioconjugated gelatin-based injectable hydrogel for biomedical applications Journal of Materials Chemistry B 3(7): 12301244.

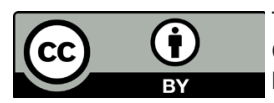

This work is licensed under Creative Commons Attribution 4.0 Licens DOI: 10.19080/JOJMS.2017.02.555585
7. Raja STK, Thiruselvi T, Sailakshmi G, Ganesh S, Gnanamani A (2013) Rejoining of cut wounds by engineered gelatin-keratin glue. Biochim Biophys Acta 1830(8): 4030-4039.

8. Welch RD, Jones AL, Bucholz RW, Reinert CM, Tjia JS, et al. (1998) Effect of recombinant human bone morphogenetic protein-2 on fracture healing in a goat tibial fracture model. J Bone Miner Res 13(9): 14831490.

9. Schultz O, Sittinger M, Haeupl T, Burmester GR (2000) Emerging strategies of bone and joint repair. Arthritis Res 2(6): 433.

10. Meischel M, Eichler J, Martinelli E, Karr U, Weigel J, et al. (2016) Adhesive strength of bone-implant interfaces and in-vivo degradation of PHB composites for load-bearing applications. J Mech Behav Biomed Mater 53: 104-118.

11. Lohmann P, Willuweit A, Neffe A, Geisler S, Gebauer T, et al. (2017) Bone regeneration induced by a $3 \mathrm{D}$ architectured hydrogel in a rat critical-size calvarial defect. Biomaterials 113: 158-169.

\section{Your next submission with Juniper Publishers} will reach you the below assets

- Quality Editorial service

- Swift Peer Review

- Reprints availability

- E-prints Service

- Manuscript Podcast for convenient understanding

- Global attainment for your research

- Manuscript accessibility in different formats ( Pdf, E-pub, Full Text, Audio)

- Unceasing customer service

Track the below URL for one-step submission https://juniperpublishers.com/online-submission.php 